\title{
Comissão Nacional da Verdade e a efetivação dos direitos à memória e à verdade histórica
}

\author{
Laís Griebeler ${ }^{1}$
}

\begin{abstract}
Resumo: 0 presente texto objetiva analisar a criação da Comissão Nacional da Verdade no ano de 2012, por meio da Lei no 12.528, de 18 de novembro de 2012, após quase 30 anos do fim do regime militar em 1985. Pretende-se verificar o lugar que esta Comissão ocupa dentro do processo de justiça de transição brasileiro, em meio à promulgação da Lei de Anistia, Lei no 6.683, de 28 de agosto de 1979, enquanto no país vigia o governo de exceção, e às medidas de reparação econômicas e simbólicas praticadas especialmente pela Comissão Especial sobre Mortos e Desaparecidos Políticos e pela Comissão de Anistia. Por fim, será analisado o papel e o potencial da Comissão Nacional da Verdade, buscando identificar qual o progresso que a sua atuação pode alcançar na efetivação dos direitos à memória e à verdade sobre as violações de direitos humanos perpetrados pelo governo de exceção.
\end{abstract}

Palavras-chave: comissão de verdade, memória, verdade histórica, ditadura militar, justiça de transição.

\section{Introdução}

Os processos de justiça de transição (ou justiça transicional) vêm sendo objetos de estudo nos últimos anos em sociedades que passaram por experiências de conflito, geralmente na transição de regimes autoritários, dentro dos quais foram cometidas graves violações dos direitos humanos, para a democracia.

De acordo com Ruti Teitel (2003, p. 69), a justiça transicional pode ser definida como a concepção de justiça associada a períodos de transformação política e caracterizada por um conjunto de iniciativas legais com o objetivo de confrontar os crimes cometidos por regimes repressores anteriores, visando reconhecer o direito das vítimas, promover a paz, alcançar a reconciliação e garantir a consolidação da democracia.

A Assembleia Geral das Nações Unidas adotou informe elaborado por Louis Joinet (Resolução 60/147 de 16 de dezembro de 2005 da Assembleia Geral das Nações Unidas) onde expõe que os direitos das vítimas de violações de direitos humanos consistem nos direitos à verdade e memória, à justiça, à reparação e às garantias de não repetição, sendo dever de todos os estados assegurá-los. 0 Conselho de Segurança da Organização das Nações Unidas entende que as medidas aplicadas podem incluir mecanismos judiciais ou não judiciais, conter a participação de organismos internacionais ou não. Ainda, podem consistir em medidas individuais ou coletivas, que ofereçam reparações econômicas, simbólicas, busca da verdade, reforma institucional, destituições de cargos, ou uma combinação destes.

Segundo Anna Mariani Carneiro Leão (2013, p. 83), a justiça de transição

$1 \quad$ Graduanda em Direito- UNICURITIBA 
pode ter diferentes finalidades, podendo ser utilizada para compensar as vítimas pela atuação arbitrária e violenta do Estado, pacificar a sociedade ou evitar que a experiência do passado se repita. A autora associa cada finalidade a um modelo: o modelo da punição pressupõe a responsabilização penal dos violadores; o modelo de anistia admite que o perdão dos crimes levaria à pacificação da sociedade e facilitaria a reconciliação; e o modelo da verdade reconhece que o esclarecimento da verdade e a preservação da memória previnem a repetição dos fatos passados.

No entanto, não há regras ou fases pré-estabelecidas para lidar com um passado de abusos, cabendo a cada sociedade determinar a sua forma de desenvolvimento do processo conforme as circunstâncias e situações concretas de cada caso.

Entre 1964 e 1985 o Brasil esteve sob o governo de uma ditadura militar, inserido em um contexto onde a repressão àqueles que se opunham ao regime e a prática de violações de direitos humanos, tais como torturas, execuções sumárias, exilamentos e cassações, faziam parte de uma política pública de estado que resultou em diversas denúncias internas e internacionais dos crimes cometidos pelo regime e que, na sua maioria, ainda não foram esclarecidos. A transição política para a democracia ocorreu de forma lenta, segura e gradual, segundo Dom Paulo Evaristo Arns (1985, p. 35), por meio de movimentos pendulares e precisamente calculados, mesclando gestos democratizantes e, em seguida, retomando medidas repressivas que mostrassem claramente o limite da abertura do regime pretendido.

Este artigo pretende analisar a criação da Comissão Nacional da Verdade no ano de 2012, como uma etapa do processo da justiça de transição no Brasil. Inicialmente, serão apresentados os questionamentos sobre a Lei de Anistia (Lei no 6.683, de 28 de agosto de 1979) no âmbito nacional e internacional, e as medidas de reparação dedicadas às vítimas de violações de direitos humanos, desde a criação da Comissão Especial sobre Mortos e Desaparecidos Políticos (CEMDP), passando pela Comissão de Anistia, até a criação da Comissão Nacional da Verdade $(\mathrm{CNV})^{2}$, por meio da Lei no 12.528, de 18 de novembro de 2011. Em seguida, analisar-se-á o papel e o potencial da $\mathrm{CNV}$ na efetivação dos direitos à memória e à verdade histórica. Para tanto, serão apresentadas as críticas a estrutura e forma de atuação das comissões de verdade, além das possibilidades de concretização dos seus objetivos.

\section{Justiça de Transição no Brasil}

O modelo brasileiro de justiça transicional, apesar das medidas de abertura política tomadas entre os governos Geisel e Figueiredo, teve como marco inicial da Verdade.

2 Será usada, a partir deste ponto do artigo, a sigla CNV para se referir à Comissão Nacional 
a aprovação de uma Lei de Anistia, que entrou em vigor no ano de 1979, enquanto prevalecia a ditadura militar, seguida de medidas de reparação às vítimas de violações de direitos humanos, concretizadas principalmente pela Comissão Especial dos Mortos e Desaparecidos Políticos e pela Comissão de Anistia. Recentemente, no ano 2012, em busca da concretização dos direitos à memória e à verdade, foi criada uma comissão de verdade.

\subsection{Anistia}

Dentre a variedade de contextos políticos em que a justiça de transição se insere, sempre há como denominador comum um legado de violações de direitos humanos. Contudo, segundo Carneiro Leão (2013, p. 83), a sanção penal dos violadores nem sempre é uma medida viável à consolidação da democracia, pois poderia desencadear mais violações e abusos de direito, e colocar em risco a frágil democracia instituída.

De acordo com Sarah Parker (2007, p. 211), em muitas transições, as autoridades abusivas do passado mantêm um grau substancial de influência política e de poder militar. Nesses casos, a probabilidade de processar e punir tais pessoas fica reduzida pelas cautelas tomadas durante a transição para evitar que acusações formais sejam feitas contra eles.

Segundo Louise Mallinder, (2011, p. 480), existe uma falta de clareza conceitual sobre a natureza das leis de anistia, isto porque o termo "anistia" pode ser definido de forma diferente dentro de cada sistema jurídico e diferentes organismos podem ser autorizados a concedê-la. Assim, o alcance e os efeitos das leis de anistia podem variar desde uma forma de fornecer reparação às vítimas das arbitrariedades de um estado repressivo até leis de autoanistia, promulgadas pelos próprios governantes ditatoriais para evitar uma sanção penal.

Glenda Mezarobba (2006, p. 28-30) expõe que, no Brasil, a pressão pela anistia fazia parte de uma reinvindicação antiga, iniciada logo após o golpe militar, num movimento crescente que envolveu diversas entidades e organizações, como a Conferência Nacional dos Bispos do Brasil, a Comissão de Justiça e de Paz, a Ordem dos Advogados do Brasil, a Anistia Internacional, além do Movimento Feminino pela Anistia e os múltiplos Comitês Brasileiros pela Anistia, para citar alguns. 0 movimento aspirava pela implementação de uma anistia ampla, para todos os atos de manifestação de oposição ao regime, geral, para todas as vítimas de atos de exceção, e irrestrita, sem discriminações ou exceções.

Entretanto, a Lei de Anistia brasileira, Lei no 6.683, de 28 de agosto de 1979, 
foi promulgada durante a vigência do regime de exceção, com a finalidade de conceder perdão aos crimes praticados por ambos os lados da confrontação, ou seja, tanto aos agentes do Estado e militares, quanto aos participantes dos movimentos de resistência. 0 objetivo era uma anistia bilateral e recíproca, pois os líderes da oposição sabiam que só poderiam passar para um regime aberto com a cooperação dos militares. Para Carneiro Leão, do ponto de vista político, a Lei de Anistia se apresentava como uma solução possível em busca da redemocratização do país.

\begin{abstract}
Era necessário e urgente trazer de volta ao Brasil os exilados, retirar milhares de pessoas da clandestinidade, liberar os presos políticos e restabelecer em seus empregos os demitidos pela perseguição política. Foi, "de alguma maneira, uma vitória da sociedade contra os atos de uma ditadura sangrenta, que durava já quase duas décadas." (CARNEIRo LEÃo, 2013, p. 61, tradução nossa).
\end{abstract}

O debate jurídico em torno da Lei de Anistia focou no conceito de crimes conexos aos crimes políticos, que foram concebidos em evidente proteção aos agentes do Estado envolvidos em atividades repressivas. Neste conceito, não há diferença entre crimes comuns e crimes políticos, ou seja, na prática, além de perdoar os crimes de resistência cometidos por perseguidos políticos que acabaram presos, exilados e banidos, a Lei de Anistia também manteve impunes os agentes do Estado responsáveis pela prática de torturas, assassinatos, sequestros, prisões ilegais e desaparecimentos forçados.

Assim, com a aprovação da Lei pelo Congresso Nacional, ocorreu uma suposta conciliação, na qual ficaram reduzidos ao mesmo denominador comum todos os crimes praticados durante o regime militar e foram perdoados sem qualquer distinção independentemente da escala ou gravidade, todos aqueles que os perpetraram.

A discussão sobre o alcance do conceito de conexão de crimes comuns aos políticos se mantém até os dias de hoje, da mesma forma quanto à validade da Lei de Anistia, que tem sido um empecilho à tentativa de conhecimento da verdade sobre os fatos ocorridos, de punição às violações de direitos humanos e de acerto de contas com o passado. A título de exemplo, em 22 de janeiro de 2013, a Comissão Interamericana de Direitos Humanos (CIDH) admitiu oficialmente o Caso Vladimir Herzog, a fim de decidir quanto à responsabilidade do Estado brasileiro pela morte e tortura do jornalista e contínua impunidade dos perpetradores (CENTRO PELA JUSTIÇA E O DiREITO INTERNACIONAL - CEJIL, 2013).

Após muitos anos do fim do regime militar, o movimento levantado pelas vítimas das violações de direitos humanos e seus familiares, acabou em 2008, pressionando o governo sob a liderança do Ex-Presidente Lula a discutir a questão em 
uma audiência pública denominada "Audiência pública sobre os limites e possibilidades para a responsabilização jurídica dos agentes violadores de direitos humanos durante o estado de exceção no Brasil".

Meses após a audiência, o Conselho Federal da Ordem dos Advogados do Brasil (OAB) apresentou perante o Supremo Tribunal Federal (STF) pedido de revisão da Lei de Anistia por meio de Arguição de Descumprimento de Preceito Fundamental (ADPF 153). 0 principal argumento da OAB foi o de que os crimes cometidos pelos agentes do Estado (torturas, assassinatos, desaparecimentos, etc.) não eram crimes políticos, mas sim crimes comuns, e que a Constituição de 1988 não havia recepcionado a interpretação segundo a qual a anistia se estendia aos agentes da repressão.

Em 2010, por maioria de 7 votos contra 2, o STF proferiu sentença entendendo que não correspondia ao Poder Judiciário modificar texto de lei, pois esta competência era apenas do Poder Legislativo, através do Congresso Nacional. Ainda, concluiu que a Emenda Constitucional no 26/1985 reafirmou o disposto na lei, e que, portanto, ambas não estariam em conflito.

Ainda, discute-se o fato da Lei de Anistia brasileira ser uma autoanistia, ou seja, ter sido promulgada durante o regime de exceção, situação completamente vedada perante os organismos internacionais de proteção aos direitos humanos. Conforme Raquel da Cruz Lima (2012, p. 202), a jurisprudência enunciada pela Corte Interamericana de Direitos Humanos (CtIDH), a partir da decisão do Caso Barrios Altos vs. Peru, afirmou a invalidade das leis de autoanistia que perdoassem graves violações de direitos humanos, por serem conflitantes com os tratados de direitos humanos e que violarem os direitos das vítimas à verdade, à justiça e à reparação, o que se depreende do trecho da sentença:

\footnotetext{
As leis de autoanistia levam ao desamparo das vítimas e à perpetuação da impunidade e por isso são manifestamente incompatíveis com a letra e o espírito da Convenção Americana. Esse tipo de lei impede a identificação dos indivíduos responsáveis por violações a direitos humanos, já que obstrui a investigação e o acesso à justiça e impede que as vítimas e seus familiares conheçam a verdade e recebam a reparação correspondente. (LiMA, 2012, p. 202-203).
}

Da mesma forma, a corte se manifestou em relação à vedação da anistia em outros casos em que era parte a Guatemala, El Salvador, Suriname, Chile, Uruguai e, no ano de 2010, o Brasil.

Após a decisão dada pelo Supremo Tribunal Federal na ADPF 153, se esgotaram as vias internas para questionar a constitucionalidade da Lei de Anistia, restando apenas as vias internacionais. Oito meses depois, em dezembro do mesmo ano, a Corte Interamericana de Direitos Humanos condenou o Brasil no Caso Gomes Lund e 
outros, conhecido como "Guerrilha do Araguaia", pelo desaparecimento de cerca de setenta guerrilheiros em campanhas militares ocorridas entre 1972 e 1975, membros do Partido Comunista do Brasil e camponeses da região, sem que seus corpos fossem encontrados, declarando inaceitáveis as disposições da Lei de Anistia brasileira e que, portanto, não possui efeitos jurídicos (SANTOS, 2010, p. 138). Todavia, abrigando-se na decisão do Supremo Tribunal, até agora o Brasil não cumpriu integralmente a condenação da Corte Interamericana de Direitos Humanos.

Mesmo após a decisão do STF, a sociedade não deixou de questionar a aplicação da Lei de Anistia e tenta, por outros meios, conseguir a responsabilização dos violadores de direitos humanos. A título de exemplo, em 2008 foi proferida sentença em relação à Ação Declaratória contra o coronel Carlos Alberto Brilhante Ustra, que foi reconhecido e declarado torturador, sem que tenha havido qualquer consequência penal (CARNEIRo LEÃo, 2013, p. 73).

Outro caso, em março de 2012, o Ministério Público Federal (MPF) denunciou o coronel do Exército Sebastião Curió Rodrigues, na Justiça Federal de Marabá - Estado do Pará, requerendo a sua responsabilização pelo sequestro de cinco pessoas na Guerrilha do Araguaia. 0 argumento utilizado pelo MPF foi o de que o coronel não estaria amparado pela Lei de Anistia, pois o crime de sequestro, por se enquadrar na categoria de crime permanente, estaria consumado enquanto não fossem encontrados os reféns ou seus restos mortais. Como até hoje não se sabe o paradeiro destas pessoas, tampouco foram encontrados os seus restos, o MPF entende que o sequestro permanece. Dessa forma, como a lei concede anistia apenas aos crimes políticos ou a eles conexos perpetrados entre 02/09/1961 a 15/08/1979, os crimes praticados pelo coronel não estariam albergados. 0 processo se encontra atualmente em sede de recurso contra decisão proferida pelo Tribunal Regional Federal da $1 \underline{a}$ Região, que entendeu estar prescrito o crime, posto que foi cometido há mais de 30 anos (TALENTo, 2013).

\subsection{Reparação}

Paulo Abrão e Marcelo Dalmás Torelly (2011, p. 216), afirmam que a Lei de Anistia previu medidas de reparação, além de apenas o perdão aos crimes políticos ou conexos praticados no período de tempo delimitado na lei, tais como a restituição dos direitos políticos, o direito ao restabelecimento do cargo público ou militar daqueles que foram arbitrariamente destituídos. No entanto, as principais medidas de reparação às vítimas da ditadura militar, apareceram apenas muitos anos após a promulgação da Lei de Anistia, apesar dos esforços das famílias das vítimas. Assim, 
somente a partir dos anos 90 a sociedade começou a reconhecer a necessidade de recompensar as vítimas e seus familiares.

Em 1994, ambos os candidatos à presidência, Luiz Inácio Lula da Silva e o ex-exilado Fernando Henrique Cardoso (FHC), firmaram o compromisso com as famílias de que, se resultassem eleitos, reconheceriam os desaparecidos políticos, assim como se esforçariam para encontrar os restos mortais das vítimas (BRASIL, 2007, p. 32).

Eleito em 1995, FHC junto ao Ministério da Justiça iniciou naquele mesmo ano as negociações com as famílias das vítimas e ONGs ligadas à causa. Nesse contexto, como resultado da luta dos familiares dos desaparecidos políticos pela responsabilização do Estado, surgiu a Lei no 9.140, de 4 de dezembro de 1995, concebida com a finalidade de reconhecer como mortas as pessoas desaparecidas que tiveram participação ou foram acusadas de participar em atividades políticas no período entre 2 de setembro de 1961 a 15 de agosto de 1979.

Mais tarde, esta lei foi emendada pela Lei no 10.875 de 1 o de junho de 2004, para reconhecer como mortos também aqueles que faleceram por causas não naturais, em dependências policiais ou assemelhadas, por repressão policial, por suicídio praticado na iminência de serem presas ou em decorrência de sequelas psicológicas resultantes de tortura.

Glenda Mezarobba (2006, p. 154) considera este o segundo momento da anistia, em que o Estado brasileiro reconheceu sua responsabilidade pelas violações de direitos humanos ocorridas durante a ditadura militar e procedeu com um "resgate moral" das vítimas do arbítrio. Segundo a autora, com a Lei no 9.140 os familiares passaram a ter o direito de requerer os atestados de óbito dos desaparecidos e o pagamento de indenizações, bastando para tanto, encaminhar um requerimento ao Ministério da Justiça.

A Lei no 9.140/95 instalou a Comissão Especial sobre Mortos e Desaparecidos (CEMDP), com o objetivo de "promover a busca de informações e a construção de instrumentos que permitam a elucidação de violações contra os direitos humanos ocorridas durante a ditadura civil-militar brasileira no período entre 1964-1985, proceder ao reconhecimento e reparação de pessoas mortas ou desaparecidas e promover a localização, a identificação e a devolução dos seus restos mortais aos familiares" (BRAsIL, Sobre a Comissão).

Os trabalhos da CEMDP podem ser divididos em duas etapas. A primeira delas se encerrou no ano de 2006 e consistiu na análise, investigação e julgamento dos processos relativos aos mortos e desaparecidos. Segundo o site oficial, a Comissão Especial já analisou 480 pedidos de reparação e reconhecimento, sendo que, dentre estes, em 362 casos foi reconhecido como causa ou circunstância da morte ou 
desaparecimento o arbítrio instalado e perpetrado pela ditadura civil-militar, pelo Estado ou por seus agentes. Os outros 118 foram indeferidos. Tal etapa resultou na publicação pela Secretaria Especial dos Direitos Humanos da Presidência da República de um livro-relatório sob o título "Direito à Memória e à Verdade" (BRASIL, Sobre a Comissão).

A segunda fase dos trabalhos consistiu na coleta de amostras de sangue dos parentes consanguíneos dos desaparecidos ou mortos cujos restos mortais não foram entregues aos familiares, para criar um banco de dados com os perfis genéticos para posterior comparação e identificação caso os corpos viessem a ser localizados.

As indenizações foram calculadas com base na expectativa de vida das vítimas mortas ou desaparecidas e totalizaram no mínimo US\$50.000 (cinquenta mil dólares), e no máximo US\$ 75.000 (setenta e cinco mil dólares). 0 prazo para apresentar requerimento perante a Comissão Especial terminou no ano de 2004.

Contudo, embora a Lei no 9.140/95 reconhecesse a responsabilidade do Estado pelas atrocidades praticadas na ditadura, esta não satisfez as expectativas dos familiares dos mortos e desaparecidos políticos. Conforme expõe Glenda Mezarobba (2006, p. 102), para os familiares se fazia necessário que a legislação previsse a ampla investigação das circunstâncias em que tais violações tomaram lugar, a identificação dos perpetradores e a consequente submissão à Justiça, além da divulgação das informações obtidas para a sociedade.

A regulamentação da condição de anistiado político ocorreu apenas com a publicação, em 13 de novembro de 2002, da Lei no 10.559, fruto da luta dos anistiados, seus familiares e políticos envolvidos com o tema.

Essa lei instaurou o Regime do Anistiado Político que garantia o direito à reparação financeira e de caráter indenizatório aos que cumpriam a condição de anistiado político nos termos da lei ou seus herdeiros, sendo contabilizado o tempo em que este esteve ausente do trabalho devido à perseguição política, assim como o direito a concluir os estudos que foram interrompidos por razões políticas ou o registro do diploma pela conclusão de curso em instituições de ensino estrangeiras, o direito à reintegração dos servidores públicos e empregados públicos, entre outros (CARNeIRo LEÃo, 2013, p. 65).

Em 28 de agosto de 2001, foi criada através da Medida Provisória no 2.151 a Comissão da Anistia, instalada no Ministério de Justiça, com a finalidade de analisar os pedidos de indenização. As reparações econômicas, segundo site oficial, foram concedidas em prestação única de valor correspondente a 30 (trinta) salários mínimos por ano de perseguição política até o limite de 100 mil reais, ou prestação mensal que corresponde ao posto, cargo, graduação ou emprego que o anistiado re- 
ceberia se o estivesse ocupando, limitado ao teto da remuneração do servidor público federal (BRAsıL, “Comissão de Anistia”).

Para o cumprimento das exigências da lei, para obter a declaração da sua condição de anistiado político e a consequente indenização, era necessário a comprovação da perseguição política e da violência sofrida pela vítima, que acabavam por resgatar os fatos que haviam sido desprezados pela Lei de Anistia. Segundo Carneiro Leão (2013, p. 65-66, tradução nossa), “[...] o pacto de esquecimento proposto pela Lei de Anistia de 1979 começou a ser revisto, abrindo caminho ao resgate de uma memória aparentemente adormecida".

A partir de então a Comissão de Anistia começou a propor políticas de resgate à memória, como a implantação de programas a exemplo do projeto Direito à Memória e à Verdade e Memórias Reveladas, que disponibilizaram registros oficiais das mortes e desaparecimentos durante a ditadura militar e arquivos do período; e o projeto Marcas da Memória, que introduz diversas ações em conjunto com a sociedade civil, reúne depoimentos e estimula iniciativas para que a sociedade conheça seu passado e evite a repetição no futuro (ABRÃo; ToRELlY 2011, p. 222).

Outras importantes iniciativas foram as Caravanas da Anistia, que consistem na realização de audiências públicas itinerantes visando percorrer todos os estados brasileiros divulgando o conhecimento histórico e mobilizando a sociedade sobre o tema, reunindo testemunhos e julgando requerimentos. E o Memorial da Anistia, que disponibiliza ao público o acervo de testemunhos gravados em vídeo e os processos julgados pela Comissão de Anistia (CARnEIRo LEÃo, 2013, p. 66).

\subsection{Verdade e memória}

Apesar das medidas tomadas pelo Estado até então, os fatos trazidos à luz pela Comissão Especial dos Mortos e Desaparecidos Políticos e pela Comissão de Anistia, somadas às críticas internacionais de que o Brasil não estaria praticando políticas de esclarecimento da verdade e da memória, no ano de 2012, quase três décadas após o fim da ditadura no Brasil, através da Lei no 12.528, de 18 de novembro de 2011, foi criada a Comissão Nacional da Verdade com o objetivo de examinar e esclarecer as graves violações de direitos humanos e efetivar o direito à memória e à verdade histórica e promover a reconciliação nacional.

A condenação do Brasil pela Corte Interamericana de Direitos Humanos no caso "Guerrilha do Araguaia” teve papel de especial relevância para a criação da CNV. Em 2010, o país recebeu a sentença internacional determinando o cumprimento de diversas obrigações, como a investigação penal dos fatos e respectivas responsabi- 
lizações, a realização de esforços para a determinação do paradeiro dos desaparecidos e entrega de seus restos mortais, o tratamento médico e psicológico das vítimas, dentre outros, a especial ênfase para a criação de uma comissão de verdade, como importante mecanismo para o esclarecimento dos fatos ocorridos, e para a construção e preservação da memória histórica, sem prejuízo da responsabilização penal dos violadores. (Corte Interamericana De Direitos Humanos, 2010, p. 114).

Dessa forma, e como resposta à comunidade internacional, a iniciativa de criar a CNV foi primeiramente sinalizada no 3o Programa Nacional de Direitos Humanos (PNDH-3), aprovado em Decreto no 7.037, de 21 de dezembro de 2009, pelo então presidente Luiz Inácio Lula da Silva. A proposta, embora tenha sido celebrada por defensores dos direitos humanos, causou certa tensão em vários setores, principalmente nas Forças Armadas, que temiam uma revisão da Lei de Anistia.

Entre os argumentos contrários à instauração de uma comissão da verdade eram que tais medidas poderiam comprometer o ambiente de conciliação nacional instituído pela Lei de Anistia em 1979 e que caso fosse constituída a Comissão, esta deveria investigar não apenas os crimes praticados pelos agentes do Estado, como o plano inicialmente previa, mas também aqueles cometidos por militantes da esquerda que combatiam o regime (Programa Nacional De Direitos Humanos 3- PHDH-3).

A resistência oriunda dos militares tinha como principal motivo o temor de que as descobertas feitas pela CNV culminassem na condenação dos agentes do governo e militares que se envolveram com violações de direitos humanos durante a ditadura, já que viam no trabalho desenvolvido pela CNV a possibilidade de um "revanchismo", ainda que reiteradamente o governo manifestasse o caráter não jurisdicional e persecutório da Comissão.

A proposta de criação da CNV, a princípio, também desagradou representantes de organizações de direitos humanos, vítimas e familiares de desaparecidos políticos. A principal crítica à Comissão residiu no fato desta não possuir poderes para responsabilizar ou punir os agentes do Estado que praticaram violações contra os direitos humanos. No entanto, os membros da CNV foram categóricos em reconhecer que a Comissão não possuía poderes para revisar a Lei da Anistia, e que estaria, em verdade, limitada por ela na questão da justiça (INSTITUTo HUMANITAS UNISINOS).

Da mesma forma, foi questionado o atraso do Brasil em instalar uma Comissão de Verdade, em relação a países vizinhos como Argentina e Chile, que criaram suas comissões oficiais logo no início do governo democrático. No Brasil, a CNV foi instalada apenas 27 anos após o fim do regime de exceção (ÚLTIMo SEGUNDO, 2012).

Demais críticas foram feitas quanto ao tempo abrangido para a investigação das violações, definido entre o período de 1946 a 1988, e não apenas o prazo que se 
prolongou o regime militar, de 1964 a 1985. Ainda, discutiu-se quanto ao pequeno quadro de pessoal disponível para o auxílio nas investigações; o prazo de apenas 2 (dois) anos de duração da CNV, que, segundo os próprios membros das comissões de verdade, seria um tempo irrisório para o cumprimento das atividades as quais a Comissão se propôs; além das dificuldades deparadas pela CNV em obter acesso aos documentos, por exemplo das Forças Armadas.

A aprovação da lei não foi uma tarefa fácil. O projeto de lei no 7.376 foi enviado em 2010 ao Congresso Nacional durante o governo Lula e foi fortemente combatida, especialmente por militares. No entanto, contou com o apoio da presidente Dilma Rousseff que se empenhou em convencer a oposição sobre a importância da matéria e apontou que a criação da comissão estava entre as prioridades do seu governo (InSTITUTo HumANITAS UNISINOS).

A pressão exercida pelos setores insatisfeitos resultou na alteração de alguns pontos do PNDH por meio do Decreto no 7.177, de 12 de maio de 2010. As mudanças no eixo de memória e verdade ocorreram na redação do plano de forma a não especificar qual dos lados, dos militares ou dos opositores, os crimes seriam apurados. Ainda, o período de investigação das violações foi ampliado de 1964 a 1985, para 1946 a 1988, e a expressão "repressão política" foi suprimida do projeto (SADI; LEMOS, 2011).

Assim, após intensa negociação, a Comissão Nacional da Verdade foi aprovada em 18 de novembro de 2011, por meio da Lei $\mathrm{n}^{\mathrm{0}}$ 12.528, com o apoio de todas as bancadas do Congresso, com a intenção de investigar e esclarecer os crimes contra direitos humanos ocorridos entre 18 de setembro de 1946 e 5 de outubro de 1988, sem, no entanto, a prerrogativa de punir os autores, e limitando a sua atuação à observância da Lei de Anistia, que segue em vigência e com interpretação inalterada perante os tribunais. 0 prazo para a conclusão dos trabalhos se esgotou no dia 16 de dezembro de 2014 e extinguiu a Comissão após a publicação de um relatório final circunstanciado, contendo as atividades realizadas, os fatos examinados, as suas conclusões a respeito e suas recomendações . $^{3}$

\section{0 papel da CNV na efetivação dos direitos à memória e à verdade}

A Comissão Nacional da Verdade, mesmo que de forma limitada, veio para suprir uma lacuna, uma deficiência da democracia brasileira, em expor publicamente as atrocidades cometidas por agentes do Estado durante a ditadura militar. Mesmo chegando atrasada, a CNV tem o potencial de abrir uma nova página no trabalho de resgate e busca da verdade, assim como de construção de uma memória coletiva

3 A íntegra do Relatório da Comissão Nacional da Verdade pode ser encontrada no endereço eletrônico do site oficial da CNV: <http://www.cnv.gov.br/>. 
sobre um período recente da história brasileira.

As Comissões de Verdade são mecanismos utilizados em períodos de transformação política a fim de concretizar os objetivos da justiça transicional, que compreendem a reforma e consolidação das instituições democráticas, a reparação das vítimas de atos de exceção, a busca pelo esclarecimento histórico e pela prática de políticas de memória e verdade, e a implementação e normalização das funções de Justiça e do Estado de Direito.

Por definição geral, são órgãos oficiais e temporários, criados para investigar abusos de direitos humanos ou humanitários, que foram cometidos ao longo de um período determinado de tempo, devendo produzir um relatório final das suas atividades contendo suas conclusões e recomendações. Ademais, não possuem jurisdição para julgar criminalmente as infrações apuradas, ainda que conhecida a identidade dos perpetradores, e devem ser detentoras de alguma autoridade que lhes permita acesso a informação (Амвоs, 2009, p. 47).

Para Sarah Parker (2007, p. 209), as Comissões de Verdade oferecem uma alternativa politicamente plausível quando julgamentos não são viáveis e anistias não são aceitas pelo público. Segundo a autora, as comissões de verdade têm como objetivo colocar os abusos de direitos humanos em um contexto histórico, ajudando a sociedade a entender como tais fatos poderiam ter acontecido. De acordo com Simone Rodrigues Pinto:

\footnotetext{
As comissões de verdade têm a responsabilidade de, ao construir a verdade por meio dos diversos testemunhos, garantir a compreensão dos eventos do passado, mas não apenas um evento específico e sim de todo um contexto mais amplo. Representa o resgate da história de um país que, em função das características próprias de um período de repressão, possui muitos eventos não esclarecidos (PINTo, 2010, p. 132).
}

Em muitos casos, um dos principais elementos de abuso é a negação por parte do regime em admitir que estes ocorreram (PARKER, (2007, p. 216). Nesse sentido, Priscilla B. Hayner (1994, p. 600) acredita que muitas comissões possuem um efeito catártico na sociedade, e cumprem com o papel de reconhecer formalmente um passado há muito tempo silenciado.

0 principal recurso para permitir que cada pessoa tenha a oportunidade de falar e contar a sua história ocorre através da coleta de depoimentos de vítimas de violações de direitos humanos, seus familiares e de militares agentes do estado do período do regime militar, por meio de audiências públicas ou encontros reservados com os membros da Comissão. A verdade sobre o passado surge da oralidade e da memória, através dos depoimentos prestados à Comissão que permitem uma rele- 
vante representação da realidade vivenciada pelo depoente, de forma que a conjugação das vozes torna possível a reconstrução histórica e da memória coletiva sobre as violações de direitos humanos perpetradas durante a ditadura militar.

Conforme Sarah Parker (2007, p. 218), muitos defensores das comissões de verdade alegam que o ato de contar a sua verdade em depoimento, expressar seus sentimentos e ter reconhecida perante um órgão oficial as violências sofridas, tem um poder curativo às vítimas que passaram boa parte de suas vidas sendo ignoradas, silenciadas e oprimidas por agentes do Estado. Da mesma forma, Simone Rodrigues Pinto (2010, p. 141), apresenta que há uma multiplicidade de estudos que mostram o poder terapêutico do ato de contar os traumas vividos, não apenas para o indivíduo que narra, mas também para toda a comunidade.

No entendimento de Raphael Neves (2012, p. 173-174), as comissões de verdade podem oferecer um meio legítimo de responsabilização, ainda que não exista a persecução penal. $\mathrm{O}$ autor considera que as Comissões de Verdade podem tomar enfoques únicos na abordagem do tema que não encontram lugar dentro do processo judicial. A título de exemplo, enquanto nos processos judiciais, em meio aos direitos do acusado em não produzir prova contra si e ao silêncio, adota-se uma dinâmica de passividade por parte do réu, quando não, a busca por parte da defesa, em levantar dúvidas sobre a acusação, em uma comissão de verdade há a desvinculação entre responsabilidade e sanção, garantindo uma maior cooperação dos violadores dos direitos humanos para a obtenção de um relato completo dos seus atos.

Outra importante abordagem que uma comissão de verdade alberga, é a possibilidade de investigação da responsabilidade daqueles que tiveram benefícios de ordem econômica durante o regime de exceção, inclusive das empresas públicas ou privadas que teriam colaborado com a sustentação do regime. Portanto, entende Neves que as comissões de verdade estão aptas a alcançar a realização dos direitos das vítimas, mesmo que em detrimento à aplicação de sanção penal.

No entanto, nem todas as comissões conseguem ser bem sucedidas em seus objetivos, por conta de limitações quanto ao acesso e confiabilidade da informação, ao tempo de mandato, quanto a restrições políticas, ou até mesmo pela insuficiência de recursos.

Ainda que restritas, Hayner entende que as comissões de verdade são amplamente utilizadas pelo fato de estabelecerem um registro justo do passado, dando voz a ambas as partes que estiveram em conflito, por entender que um relato honesto da violência vivenciada impede que a história seja perdida, auxilia na reconciliação nacional e permite que a sociedade aprenda com seu passado, evitando a repetição das violências no futuro. No mesmo sentindo, Sarah Parker (2007, p. 220-221) indica 
que a publicação dos relatórios das Comissões de Verdade fornece um roteiro para a proteção futura dos direitos humanos, apresentando ideias sobre como prevenir novos abusos e sugerindo reformas judiciais e na estrutura das instituições de segurança pública, como a polícia militar.

Enfim, conclui Kai Ambos (2009, p. 51) que as comissões de verdade conseguem ter um enfoque múltiplo para os problemas que surgem em sociedades inseridas em contextos de transição, esclarecendo a verdade sobre casos individuais e coletivos, apontando as causas por trás das violações de direitos humanos e responsabilizando os violadores, ainda que fora da esfera penal. Nas palavras de Ruti Teitel (2003, p. 18-19), revisitar o passado é uma maneira de seguir em frente, e, para isso, é necessário repensar o significado social dos conflitos ocorridos, em uma tentativa de reconstruir os seus efeitos presentes e futuros.

No cenário da memória da ditadura militar de 1964 a 1985, Comissão Nacional da Verdade é criada não com a intenção de impor uma história, mas considerando que não existe uma única verdade sobre os fatos, visa trazer a tona uma memória que ficou esquecida perante a história oficial, contada por aqueles que controlaram a transição para o regime democrático.

A CNV, então, abre o campo para uma reinterpretação da história, reconhecendo que até o momento, apenas um dos lados teve a oportunidade de falar, e criando um espaço para que o outro lado tenha voz, a fim de que este passo da justiça transicional concretize o direito à verdade e à memória. Esse resgate da memória é essencial para que a sociedade brasileira se aproprie do seu passado e consiga superar as violências e violações de direitos humanos que fazem parte da nossa história.

Assim, o trabalho da CNV é apenas um esforço inicial, uma vez que não conta com o tempo necessário à investigação da totalidade dos fatos e a falta de colaboração de certos órgãos públicos quanto à entrega de documentos dificultam uma atuação livre e completa. No entanto, a iniciativa da Comissão abre o caminho para que a questão da memória e da verdade sobre esse período obscuro da nossa história seja discutido e investigado pela sociedade, que, se apropriando das informações reveladas pela $\mathrm{CNV}$, pode dar continuidade ao trabalho, para que ao final do processo de justiça transicional não seja deixado espaço para silêncios e negações de acontecimentos da nossa história.

\section{Considerações Finais}

A criação de uma Comissão de Verdade como passo da justiça de transição tem um grande potencial no que se refere à construção de uma verdade histórica e ao 
resgate da memória silenciada sobre eventos traumáticos da história do nosso país.

O processo de justiça de transição, como o conjunto de iniciativas em busca do enfrentamento de um período passado marcado por graves violações de direitos humanos, no Brasil, até 2012, havia se dedicado, na sua maioria, em medidas de reparação econômica e simbólica constantes das Leis no 9.140/1995, 10.559/2002 e 10.875/2004, que instituíram a Comissão Especial dos Mortos e Desaparecidos Políticos e a Comissão de Anistia, ambas atuantes até os dias de hoje, cada qual cumprindo um papel fundamental no desenvolvimento da transição ao patamar que chegamos hoje; e na promulgação da controvertida Lei de Anistia, que mesmo após a decisão do Supremo Tribunal Federal quanto a sua interpretação, ainda gera discussões de proporções nacionais e internacionais. Contudo, uma medida efetiva focada na busca da verdade ainda não havia sido implementada após quase 30 anos do fim do governo de exceção em 1985.

Embora, em comparação aos países vizinhos, como a Argentina e Chile, o Brasil tenha seguido um processo muito lento até alcançar o entendimento sobre a importância de zelar pelos direitos das vítimas e seus familiares em conhecer a verdade sobre as circunstâncias dos fatos dolorosos por elas vivenciados, assim como, a compreensão quanto à necessidade de toda a sociedade em conhecer o seu passado coletivo de violência sistemática e violação de direitos humanos, enfim, foi incluída no plano de governo a instalação de uma comissão de verdade.

Nesse contexto, foi criada a Comissão Nacional da Verdade que, embora cercada de críticas desde os primeiros indícios do seu surgimento, possui a difícil e complexa missão de dar impulso à busca dessas memórias abafadas para retirá-las da obscuridade e divulgá-las a sociedade, através da publicação do relatório final que se deu no mês de dezembro de 2014.

Mesmo lutando contra o relógio para o cumprimento dos trabalhos no prazo exíguo estipulado para a sua permanência, e mesmo com as dificuldades de acesso aos documentos das Forças Armadas e organismos afins, esse trabalho se propôs a demonstrar o inegável valor que as atividades da CNV possuem para a sociedade no presente e quanto poderia influenciar na determinação do futuro, pois, por mais que tenhamos conseguido suplantar a ditadura militar por um regime democrático de governo, a sociedade brasileira ainda convive com sequelas do autoritarismo que restaram da ditadura militar, como as violências sistemáticas e torturas presentes diariamente nos noticiários, em muito por conta da falta de uma memória coletiva e da discussão e investigação dos crimes cometidos pela ditadura militar.

Diante dessas conclusões, verifica-se que a transição brasileira ainda é um processo em trâmite, e que a instalação da Comissão Nacional da Verdade tem o po- 
tencial de iniciar mudanças na nossa democracia, a partir do resgate da memória e da verdade, no entanto, a continuidade desse trabalho ficará a cargo de toda a sociedade.

\section{Referências bibliográficas}

ABrão, P.; ToRelly, M.D. (2011). As dimensões da justiça de transição no Brasil, a eficácia da lei de anistia e as alternativas para a verdade e a justiça. In: A Anistia na Era da Responsabilização: o Brasil em perspectiva internacional e comparada. Brasília, Ministério da Justiça, Comissão de Anistia; Oxford University, Latin American Centre, 2011, p. 212-248.

Aмвоs, K. (2009). El marco jurídico de la justicia de transición. Justicia de transición: com informes de américa latina, alemania, italia y espana. Montevideo: Fundación Konrad-Adenauer, p. 23-129.

Arns, D.(Org.). (1985). Projeto Brasil Nunca Mais. Disponível em: <http://dhnet.org. br/w3/bnm/tomo_ii_vol_1_a_pesquisa_bnm.pdf>. Acesso em 25 fev. 2014.

Brasil(2007). Secretaria Especial dos Direitos Humanos. Comissão Especial sobre Mortos e Desaparecidos Políticos. Direito à verdade e à memória: Comissão Especial sobre Mortos e Desaparecidos Políticos. Brasília: Secretaria Especial dos Direitos Humanos.

Brasil (2009). Decreto no 7.177, de 12 de maio de 2010. "Altera o Anexo do Decreto no 7.037, de 21 de dezembro de 2009, que aprova o Programa Nacional de Direitos Humanos - PNDH-3". Diário Oficial da República Federativa do Brasil, Brasília, DF.

Brasil. Comissão de Anistia. Ministério da Justiça. Disponível em: <http://portal. mj.gov.br/ANISTIA//data/Pages/MJABFF735EITEMID48C923D22C804143AB475A47E582E1D8PTBRIE.htm>. Acesso em 05 jul. 2014.

Brasil. Sobre a Comissão. Comissão Especial sobre Mortos e Desaparecidos Políticos. Disponível em: <http://cemdp.sdh.gov.br/modules/wfchannel/index.php?pagenum=1>. Acesso em 03 jul. 2014.

CARneiro LeÃo, A.M. (2013). La Comisión de la Verdad en la trayectoria de la justicia transicional en Brasil. Revista Derecho del Estado, Bogotá, n. 30, p. 55-92.

Centro pela Justiça e o Direito Internacional - CEJIL. (2013). Comissão Interamericana admite caso Herzog e passa a analisar responsabilidade do Estado pelas violações denunciadas. Disponível em: <http://cejil.org/pt-br/comunicados/comissao-interamericana-admite-caso-herzog-e-passa-a-analisar-responsabilidade-do-estado>. Acesso em 26 ago. 2014.

Conselho de Segurança da Organização das NaÇões Unidas. (2004). Report Secretary General Transitional Justice. Disponível em: <http://www.unrol.org/fi- 
les/2004\%20report.pdf>. Acesso em 02 mar. 2014.

Corter Interamericana De Direitos Humanos (2010). Caso Gomes Lund e outros vs. Brasil. Sentença de 24 de novembro, p. 114. Disponível em: <http://www.sdh.gov. br/assuntos/atuacao-internacional/sentencas-da-corte-interamericana/sentenca-araguaia-24.11.10-1>. Acesso em: 25 mai. 2015.

HAYNER, P.B. (1994). Fifteen truth commissions - 1974 to 1994: a comparative study. Human Rights Quarterly, v.16, n.4, p. 597-655.

InSTITUTO Humanitas UNISINOS Conjuntura da semana. "comissão da verdade": uma comissão da verdade e da memória, mas não da justiça". Disponível em: <http://www. ihu.unisinos.br/cepat/cepat-conjuntura/509987-conjuntura-da-semana-comissao-da-verdade-uma-comissao-da-verdade-e-da-memoria-mas-ainda-nao-da-justica>. Acesso em 29 ago. 2014.

LiMA, R.C. (2012). A emergência da responsabilidade criminal individual no sistema interamericano de direitos humanos. Lua Nova, São Paulo, n. 86, p. 187-219.

MALLINDER, L. (2011). Perspectivas transicionais sobre as anistias. In: A anistia na era da responsabilização: o Brasil em perspectiva internacional e comparada. Brasília: Ministério da Justiça, Comiss ão de Anistia; Oxford University, Latin American Centre, p. 470-505.

MezarobBA, G. (2006). Um acerto de contas com o futuro: a anistia e suas consequências - um estudo do caso brasileiro. São Paulo, Humanitas/Fapesp.

Moura, M. T. R. A.; Zilli, M. A. C.; GHidalevich F. G. M. (2009). "nformes Nacionales: Brasil. In: Justicia de transición: con informes de américa latina, alemania, italia y espana. Montevideo: Fundación Konrad-Adenauer, p. 171-199.

Neves, R. (2012). Uma Comissão da Verdade no Brasil? Desafios e perspectivas para integrar direitos humanos e democracia. Lua Nova, São Paulo, n. 86, p. 155-186.

PARKER, S. (2007). All aboard the truth bandwagon: an examination of our fascination with truth commissions. Antipoda Revista de Antropologia y Arqueologia, Bogotá, $\mathrm{n}$. 4, p. 207-224.

Pinto, S. R. (2010). Direito à memória e à verdade: comissões de verdade na América latina. Revista Debates, Porto Alegre, v. 4, n. 1, p. 128-143.

Programa Nacional de Direitos Humanos - PHDH-3. Entenda a polêmica sobre a Comissão Nacional da Verdade. Disponível em: <http://pndh3.com.br/clipping/entenda-a-polemica-sobre-a-comissao-nacional-da-verdade/>. Acesso em 29 ago. 2014.

SAntos, C. M. (2010). Questões de justiça de transição: a mobilização dos direitos e a memória da ditadura no Brasil. In: Repressão e memória política no contexto íbero- 
-brasileiro: estudos sobre Brasil, Guatemala, Moçambique, Peru e Portugal. Brasília: Ministério da Justiça, Comissão de Anistia; Portugal: Universidade de Coimbra, Centro de Estudos Sociais, p. 129-151.

SAdI, A.; Lemos, I. (2011). Câmara aprova a criação da Comissão da Verdade. Globo. com. Disponível em: <http://g1.globo.com/politica/noticia/2011/09/camara-aprova-criacao-da-comissao-da-verdade.html>. Acesso em 22 fev. 2014.

TALENTO, A. (2013). Tribunal decide suspender ação contra Curió por desaparecimentos durante a ditadura. Folha de São Paulo. Disponível em: <http://www1.folha.uol.com. br/poder/2013/12/1379786-tribunal-decide-suspender-acao-contra-curio-por-desaparecimentos-durante-a-ditadura.shtml>. Acesso em 19 jun. 2014.

Teitel, R. G. (2003). Transitional Justice Genealogy. Harvard Human Rights Journal. Cambridge, v. 16, p. 64-94.

Último Segundo (2012). Comissão da Verdade não vai punir, diz integrante. Disponível em: <http://ultimosegundo.ig.com.br/politica/2012-05-12/comissao-da-verdade-nao-vai-punir-diz-integrante.html>. Acesso em 21 fev. 2014.

Recebido em Abril/2015

Aprovado em Dezembro/2015 